\title{
Head Injury in a Child : A Rare Combination of "Three-in-one" Complications
}

\author{
Abdul Rashid Bhat, Altaf R.Kirmani, Tariq H.Raina, Mohammed Afzal Wani, Altaf Ramzan, Sajad Arif, Sheikh Javed and \\ Shafiq Alam \\ Department of Neurosurgery, Sher-i-Kashmir Institute of Medical Sciences, Srinagar.
}

\section{ABSTRACT}

A three year old female child presents with a rare combination of three complications, two months after closed head injury. The linear fracture grew into a leptomeningeal cyst and a large brain abscess leads to hydrocephalus by causing ventriculitis thereby increasing the size of leptomeningeal cyst. J Med Sci 2009;12(2):56-57

Key words: Child, Closed head injury, Leptomeningeal cyst, Brain abscess, Hydrocephalus

\section{Introduction}

The complications of head injuy are very common and range from neurodeficits to CSF fistulas, endocrine and calvarial defects. The uncommon and rare complications are also reported. The number of compli-cations in a single case has varied from one to two in closed head injury to more than two in the open head injury. Moreover the childhood complications of head injury also vary from adults. The department of neurosurgery, Sher-iKashmir Institute of Medical Sciences, Kashmir presents a casechild of closed head injury with three complications in a rare combination.

\section{Case Report}

A three year old female child suffered head injury due to fall from one storey. At the presentation to the Deptt. Of Neurosurgery, SKIMS Kashmir, the child was having a GCS (Glasgow Coma Scale) score of 8 and there was a small cephahematoma on the right parietal area, leaving the skin intact and injury closed. An urgent CT-Scan head revealed right

Reprint Request:

Dr. Abdul Rashid Bhat

Associate Professor

Department of Neurosurgery

SKIMS, P.B. 27, Srinagar-190011 (Kashmir)

E-mail:seven_rashid@rediffmail.com parietal cephalhematoma, a linear fracture and a small underlying parietal lobe haemorhagic contusion and a little bigger than this on the opposite side (Fig. 1). The hospital stay was uneventful till her recovery to a GCS of 12 within two weeks and discharge from hospital. Two months later, the child presented to the hospital with the history of vomiting, listlessness, unable to thrive and a swelling on the right side of the head. The examination revealed that child was afebrile with a GCS of 10 and had developed a boggy pulsatile swelling on the right parietal area of head (old fracture site). The CT-Scan head showed: (1) a growing skull fracture with leptomeningeal cyst, (2) a large abscess cavity in right parietal lobe, just underneath the fracture and (3) hydrocephalus (Fig. 2, 3). The child was subjected to the external ventricular drainage followed by excision of abscess and repair of duramater. The external drainage was later converted to a ventriculo-peritoneal shunt. She recovered fully and was discharged.

\section{Discussion}

The diastasis of skull sutures in children, after head injury, usually present as linear fractures. These diastatic linear skull fractures sometimes exibit a characteristic triad of findings. These are diastatic skull fractures with margins separated by at least $4 \mathrm{~mm}$, overlying scalp swelling disproportionate to the fracture underlying and contrlateral neurodeficit. These are growing skull fractures (or leptomeningeal cyst). ${ }^{1} \quad$ The brain abscess is uncommon in the closed head injuries. Brain abscess 


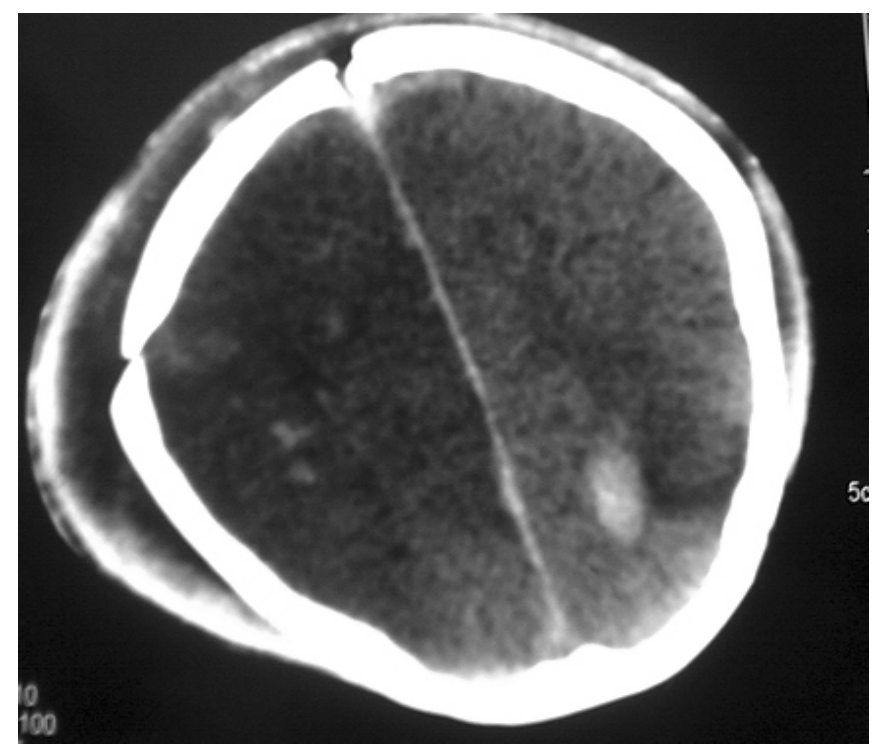

Figure 1: Plain CT-scan head showing right parietal cephal-hematoma, parietal bone linear fracture and biparietal lobar contusion

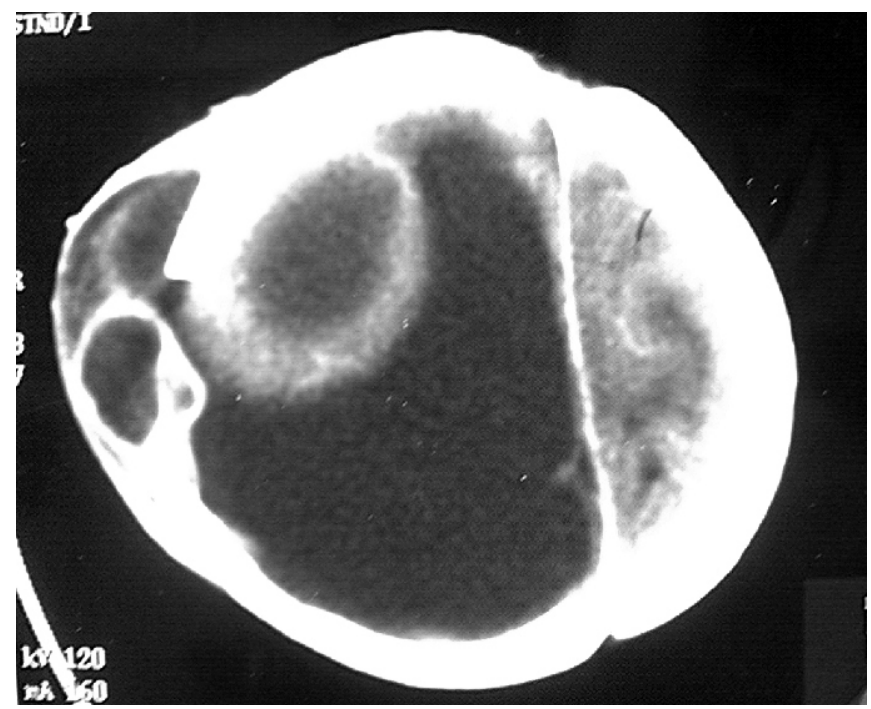

Figure 2: Plain CT-scan head two months after head injury, depicting growing skull fracture with leptomeningeal cyst, abscess cavity and hydrocephalus

commonly occurs due to the penetrating missile wounds, infection in an intracerebral hematoma, retained foreign bodies and extension from infections of the skull, skull or meninges. ${ }^{2,3}$ The brain abscess can develop many years after the head injury due to the missiles and their fragment ${ }^{4,5,6}$ The hydrocephalus due to the pyogenic infections of brain is very low in the list of causes. The most common cause being the obstruction to the CSF pathways due to intracranial space occupying lesions. ${ }^{7}$ Gupta et al 1988, reported a case of hydrocephalus due to obstruction of foramen Monro by brain abscess in a child with cyanotic heart disease. ${ }^{8}$ The child had closed head injury with a linear fracture and a small contusion. Since leptomeningeal cysts always require dural tear to occur, the defect in the dura was primary in this patient. The cause of abscess in our patient is most likely due to the opportunistic infection in an existing small haemorrhagic

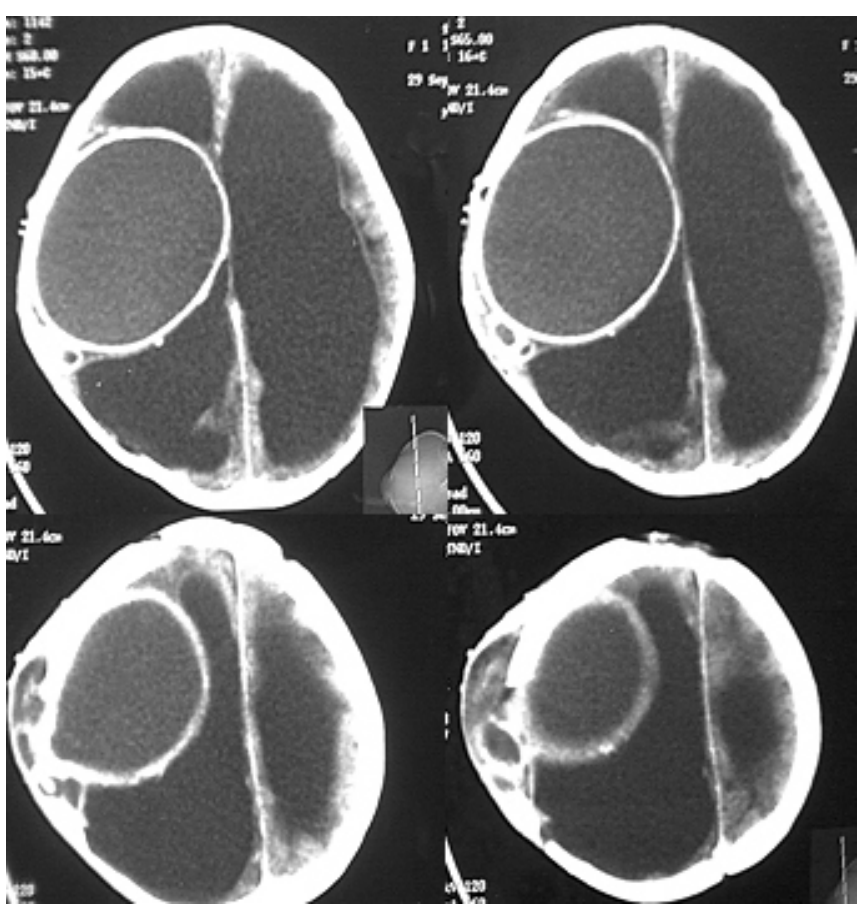

Figure 3: Plain CT-scan head of the same child with all three findings in one (Leptomeningeal cyst, abscess and hydrocephalus)

contusion. Lowered immunity in such a child is expected to allow mild infection to grow over a period of time. The hydrocephalus could be caused by subclinical ventriculitis without fever and the obstruction due to mass effect by the large abscess cavity. However traumatic osteomylitis in acute head injuries could also be the cause of brain abscess in presence of dural tear.

\section{References}

1. Thompson JB, Mason TH, Hains GL et al. Surgical management of diastatic linear skull fractures in infants. $\mathcal{F}$ Neurosurg 1973;39:439.

2. Prakash S. Intracranial abscess in the armed forces. Neurol (India) 1977;25:126.

3. Tandon PN. Surgery for sequelae of head injury. Neurol (India) 1977;25:126.

4. Grant FC. Post-traumatic brain abscess. In: Injuries of the brain, spinal cord and their coverings. (Eds.) Brock S Cassell. 1960:203.

5. Robinson EF, Moiel RH, Gol A. Brain abscess 36 years after head injury. F Neurosurg 1968;28:166.

6. Tomlison BE. In : Acute injuries of the head. (Ed.) Rowbotham GF. E A S Livingstone. 1964: p93.

7. Bernard R, Coigent J, Pinsard NR et al. Hydrocephalus in the infants caused by intracranial mass lesions. Sem Hop Paris 1966; 42:2119.

8. Gupta AK, Sharma R. Ipsilateral progressive hydro-cephalus due to acquired foramen Monro obstruction - An unusual complication of brain abscess in cyanotic heart disease. Neurosurgery 1988;22: 154.

9. Rowbotham GF. Traumatic osteomyelitis. In: Acute injuries of the head. (ed.) Rowbotham GF. E A S Livingstone. 1964: p353. 